\title{
The Relations Between Non-motor Symptoms and Motor Symptoms in Parkinson Disease
}

\author{
OANA CRICIOTOIU ${ }^{1}$, DIANA IULIA STANCA ${ }^{2 *}$, DANIELA GABRIELA GLAVAN ${ }^{3}$, SIMONA BONDARI4, RAMONA DENISE MALIN 5 , \\ MIRCEA SORIN CIOLOFAN 5 , MARIUS GABRIEL BUNESCU, FLORIN MARIUS ROMANESCU7, MICHAEL SCHENKER ${ }^{8}$, \\ OVIDIU STEFAN GEORGESCU ${ }^{1}$, MANUELA IULIANA DRAGOMIR ${ }^{9}$, VICTOR GHEORMAN ${ }^{10}$, VERONICA GHEORMAN ${ }^{11}$, \\ DAN IONUT GHEONEA ${ }^{12}$ \\ 'University of Medicine and Pharmacy of Craiova, Doctoral School, 2 Petru Rares Str., 200349, Craiova, Romania \\ 2University of Medicine and Pharmacy of Craiova, Faculty of Medicine, Department of Neurology, 2 Petru Rares Str., 200349, \\ Craiova, Romania \\ ${ }^{3}$ University of Medicine and Pharmacy of Craiova, Faculty of Medicine, Department of Psychiatry, 2 Petru Rares Str., 200349, \\ Craiova, Romania \\ 4University of Medicine and Pharmacy of Craiova, Department of Radiology and Medical Imaging,, County Hospital of Craiova, \\ 1 Tabaci Str.,200642, Craiova, Romania \\ 5University of Medicine and Pharmacy of Craiova, Faculty of Medicine, Department of ORL, 2 Petru Rares Str., 200349, Craiova, \\ Romania \\ ${ }^{6}$ University of Medicine and Pharmacy of Craiova, Faculty of Medicine, Occupational Medicine Department, 2 Petru Rares Str., \\ 200349, Craiova, Romania \\ 7University of Medicine and Pharmacy of Craiova, Department of Physiology, 2 Petru Rares Str.,200349, Craiova, Romania \\ \&University of Medicine and Pharmacy of Craiova, Oncology Department, 2 Petru Rares Str., 200349, Craiova, Romania \\ 'University of Medicine and Pharmacy of Craiova, Department of Public Health and Healthcare Management, 2 Petru Rares \\ Str.,200349, Craiova, Romania \\ ${ }^{10}$ University of Medicine and Pharmacy of Craiova, Psychiatry Department, Neuropsychiatry Hospital of Craiova, 24 Aleea Potelu \\ Str., 200473, Craiova, Romania \\ ${ }^{11}$ University of Medicine and Pharmacy of Craiova, Department of Cardiology, 2 Petru Rares Str.,200349, Craiova, Romania \\ 12University of Medicine and Pharmacy of Craiova, County Hospital of Craiova, Gastroenterology Department, 1 Tabaci Str.,200642, \\ Craiova, Romania
}

\begin{abstract}
The aim of this study was to evaluate the correlation between motor and non-motor symptoms in patients diagnosed with Parkinson. We included in ourstudy 72 patients diagnosed with Parkinson disease:28 female and 44 males. Each patient was evaluated using Non-motor Symptoms Questionnaire for Parkinson Disease, for motor status we used Unified Parkinson Disease Rating Scale (UPDRS) part 3 (motor part). The results of our study indicated that there is a correlation between the non-motor state and the motor symptoms but not in all non-motor domains. The study indicates that the digestive symptoms, the, cardiovascular, sleep and miscellaneous correlate with the motor symptoms but urinary symptoms, memory, hallucination, depression and sexual dysfunction does not show an interdependence with the motor state.
\end{abstract}

Keywords: Parkinson disease, non-motor symptoms, motor symptoms

Parkinson disease (PD), one of the most common neurodegenerative disease, is classified as a movement disorder, but non-motor symptoms (NMS) also occur[1].

Traditionally, PD is characterized by its motor symptoms: bradykinesia, resting tremor and rigidity, but, in last decades, this concepthas changed and now the disease is regarded as much a non-motor disorder as a motor disorder. Several studies showed that NMS are a real burden in PD which may appear even before the diagnosis of PD and that these NMS reflect a key determinant of the patient and career's quality of life [2].

Increasing data showed thatPD is a multisystem disease rather than a disease and this is due to it's multi-focal and multi-neurotransmitter driven pathology. The clinical phenotypic variations of PD are variable, and this is, in part, the consequence of a wide range of NMS which can include sleep dysfunction, psychiatric disorders, gastrointestinal dysfunction or autonomic dysfunction. Butthe change that underlie the NMS is still poor understand and they are not treated effectively well with dopamine-based drug therapy[3-5].

It is well known that motor symptoms affect quality of life in PD patients, but many reports have suggested that NMS can have a greater influence on the patient's life than the motor symptoms. It is important to assess the presence of motor and non-motor symptoms and to evaluate the impact of these symptoms on quality of life[ 6-7].

The purpose of our study was to evaluate the distribution and correlations of the two types of symptoms.

\section{Experimental part \\ Methods and Materials}

We included in our study 72 patients ( 28 females and 44 males), mean age $67.56 \pm 7.74$ (range between 49 and 80 years, diagnosed with Parkinson Disease in according with United Kingdom Society Brain Bank criteria[8]. For each patient we recorded details of demographic data, age at onset, disease duration, symptoms at onset, medications, motor fluctuations and family history. The patients were assessed using United Parkinson Disease Rating Scale motor section (UPDRS part III) [9]. This scale is an instrument with 27 items which assessed motor function related to tremor, rigidity, posture and bodily movement. Scores range from 0 to 108 points and higher scores indicate lower motor functioning. [10].

The Hoehn and Yahr Scale was used for disease staging 
Both scale (UPDRS and Hoehn and Yahr scale) were evaluated while the patients were in best on state.

To evaluate the non-motor symptoms, each patient was assessed by Non-motor Symptoms Questionnaire for Parkinson Disease (NMS Quest) [11]. It is a self-assessing tool that includes 30 questions covering 10 different domains ranging from gastrointestinal to miscellaneous. This questionnaire must be completed by the patient, checking the no or yes box. We rated 0 point if the patient's answer was no and 1 point if the patient's answer was yes.

For the memory impairment we used Mini-Mental State Examination (MMSE) test [12-13].

To evaluate sleep dysfunction the patients took the Parkinson Disease Sleep Scale(PDSS)[14].

The statistical analysis was made using IBM SPSS Statistics V20.

We performed both descriptive and exploratory data analysis. For comparations we used one tailed student Ttestand for correlation - Pearson R test, with the statistically significance established at 95\%, $p<0.05$.

\section{Results and discussions}

The present study evaluated PD patients that preformed our protocol from 2017 to 2019. There were included 34 from rural environment and 38 urban. When evaluated the disease progression there were included patients from stage 1 to stage $5 \mathrm{H} \& Y$ with an medium distribution around stage 3.

The aim of this study was to analyze the relation between the two types of symptomatology in PD, motor and non-motor.

In the figure 1 we can observe that there was a positive correlation between the motor and non-motor state of our patients. This means that as the motor symptomatology accentuate the non-motor one follows the same trend.

Table 1

CORRELATION BETWEEN NMSQ AND UPDRS PART III Centebinoes

\begin{tabular}{|c|c|c|c|}
\hline & & $\begin{array}{c}\text { UPDRS PAR } \\
T_{\text {II }}\end{array}$ & tasso \\
\hline \multirow{3}{*}{ UPDRS_PART_JI } & Pkarson Correlabon & 1 & 312 \\
\hline & sig. (2-taind) & & $90 \mathrm{a}$ \\
\hline & N & 72 & 72 \\
\hline \multirow[t]{3}{*}{ Nuso } & Pearson Cortelabon & $312^{\prime \prime}$ & 1 \\
\hline & $\sin (2 \tan \phi)$ & .008 & \\
\hline & N & 72 & 1048574 \\
\hline
\end{tabular}

- Comelaton is signthart at he 0.01 level (2-taled)

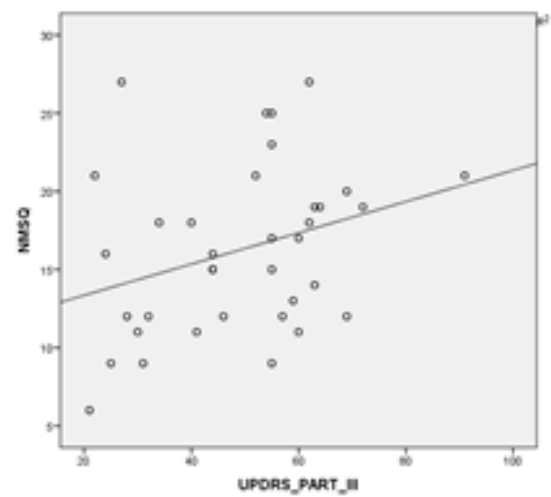

Fig.1. Correlation between NMSQ and UPDRS part III

In the table above we observe that there was an correlation with an statistical significance with $p=0.008$ (table 1).

Given the literature data that not all non-motor features correlate with the motor ones, we went further to analyze the different domains of NMSQ to compare it with the motor state of our patients.

There was no surprise to realize that not al NMSQ domains correlated with the motor UPDRS.

In the table below we can observe an positive correlation when it comes to digestive, cardiovascular, sleep and miscellaneous domains. On the other side the urinary, memory, hallucination, depression and sexual function domain did not correlate. On the positive correlation we had an statistical significance established with $p<0.05$ (table 2).

We went further and considered that for the memory and sleep we can better analyze it with the validated questionnaires for each one.

We observed that for the sleep dysfunction there was an negative correlation with the motor UPDRS, with $p$ value of 0.03 . This negative correlation can be explained by the fact that the PDSS questionnaire has an decrease of the score as the dysfunction accentuate and the UPDRS part III score increases as the motor symptoms progresses. This significate that there is an relation between the sleep and motor dysfunction (table 3, fig. 2).

When it comes to memory there was no correlation with the motor UPDRS. This shows that the memory domain evaluated with the NMSQ showed the same correlation status as the validated questionnaire for memory (MMSE), showing thatMNSQ domains can proper evaluate the non-motor state(table 4, fig. 3).

Table 2

CORRELATION BETWEEN NMSQ DOMAINS AND UPDRS PART III

Contelations

\begin{tabular}{|c|c|c|c|c|c|c|c|c|c|c|}
\hline & & $\begin{array}{c}\text { Digestive_sy } \\
\text { motoms }\end{array}$ & Uinan & Netmer & Hallycinason & Descresion & $\begin{array}{c}\text { Serwal_funct } \\
\text { of }\end{array}$ & $\begin{array}{c}\text { Cardiovascul } \\
\text { at }\end{array}$ & Sltep & $\begin{array}{c}\text { Miscellaneou } \\
\$\end{array}$ \\
\hline \multirow[t]{3}{*}{ UPDAS_PART_Ji } & Pearson Coetelasson & 361 & .146 & .139 & 174 & -.094 & .029 & .298 & 284 & 270 \\
\hline & sag (2-tales) & .602 & .220 & .243 & .143 & 432 & 851 & .019 & .025 & 022 \\
\hline & $N$ & 72 & 72 & 72 & 72 & 72 & 72 & 72 & 72 & 72 \\
\hline
\end{tabular}

Table 3

CORRELATION BETWEEN PDSS AND UPDRS PART III
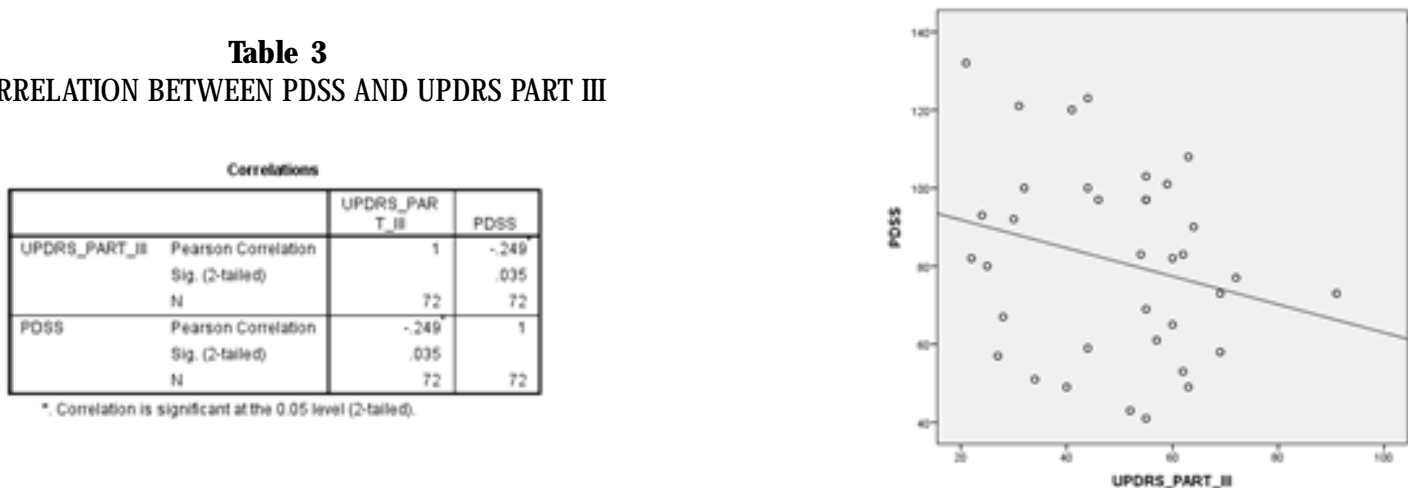

Fig.2. Correlation between PDSS and UPDRS part III 
Table 4

CORRELATION BETWEEN MMSE AND UPDRS PART III

Correlations

\begin{tabular}{|ll|r|r|}
\hline & $\begin{array}{r}\text { UPDRS_PAR } \\
\text { T_III }\end{array}$ & MMSE \\
\hline UPDRS_PART_II & Pearson Correlation & 1 & -179 \\
& Sig. (2-tailed) & & .133 \\
& N & 72 & 72 \\
\hline MuSE & Pearson Correlation & -.179 & 1 \\
& Sig. (2-tailed) & .133 & \\
& N & 72 & 72 \\
\hline
\end{tabular}

This study shows that the incomplete discovery of the pathophysiology process of PD has an impact on those patients disease management. It is important that we treat both motor and non-motor symptoms to offer our patients the best quality of life possible in their stage of the disease.

As in our study, other findings showed that there is a correlation between the motor and non-motor symptoms[15-16].

When it comes to sleep the literature is mentioned that even if the patients report an improve of motor function when the sleep dysfunction diminuates, there is no objective improvement of the motor function [17-19]. In our study there was an correlation between those two[20].

The memory impairment is linked in other studies to the progression of the motor state but in this study there was no statistical correlation between those two[21].

This shows that both motor and non-motor symptoms affect the quality of life of PD patients and the case management should be made by an multidisciplinary team.

\section{Conclusions}

Patients with PD have an variety of symptoms that should be recognized and treated. In this study we headlighted that some of the non-motor symptoms correlate with the motor state of our patients, amoung them there are digestive, cardiovascular, sleep and miscellaneous domains. On the other side some of the symptoms does not present an interdependence with the motor symptoms as urinary, memory, hallucination, depression and sexual function domain, and it should be treated separately.

\section{References}

1.LEDETI, A., VLASE, G., CIRCIOBAN, D., LEDETI, I., STELEA, L.,VLASE, T., Comparative Stability of Levodopa Under Thermal Stress in both Oxidative and Inert Media, Rev. Chim. (Bucharest), 67, 2016, p. 26482650.

2.TITOVA, N., PADMAKUMAR, C., LEWIS, S. J. G., CHAUDHURI, K. R., Parkinson's: a syndrome rather than a disease?, Journal of Neural Transmission, vol. 124, 2017 , pp. 907-914.

3.SAVICA, R., CARLIN, J. M., GROSSARDT, B. R., BOWER, J. H., AHLSKOG, J. E., MARAGANORE, D. M., BHARUCHA, A. E.,ROCCA, W. A., Medical records documentation of constipation preceding Parkinson disease: A case-control study, Neurology, vol. 73, 2009 , pp. 1752-1758.

4.CSOTI, I., JOST, W. H., REICHMANN, H., Parkinson's disease between internal medicine and neurology, Journal of Neural Transmission, vol. 123, 2016, pp. 3-17.

5.SCHEPERJ ANS, F., AHO, V., PEREIRA, P. A. B., KOSKINEN, K., PAULIN, L., PEKKONEN, E., HAAPANIEMI, E., KAAKKOLA, S., EEROLA-RAUTIO, J., POHJA, M., KINNUNEN, E., MURROS, K., AUVINEN, P., Gutmicrobiota are related to Parkinson's disease and clinical phenotype, Movement Disorders, vol. 30, 2015.

6.HAND, A., WILLIAMS, A. J., SCHAPIRA, A. H. V., STOCCHI, F., ABE, K., CHAUDHURI, K. R., MACPHEE, G., NAIDU, Y., BARONE, P., SETHI, K., RYE, D., TLUK, S., TSUBOI, Y., CLAYTON, L., MACMAHON, D., BROWN, http://www.revistadechimie.ro

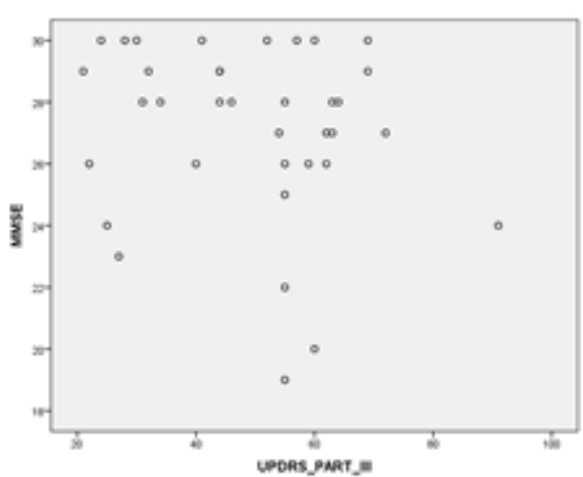

Fig.3. Correlation between PDSS and UPDRS part III

R. G., MARTINEZ-MARTIN, P., ODIN, P., BONUCCELLI, U., RABEY, M., THOMAS, S., BREEN, K., ONDO, W., OLANOW, C. W., FORBES, A., Prevalence of nonmotor symptoms in Parkinson's disease in an international setting; Study using nonmotor symptoms questionnaire in 545 patients, Movement Disorders, vol. 22, 2007 , pp. 1623-1629. 7.SCHRAG, A., J AHANSHAHI, M., QUINN, N., What contributes to quality of life in patients with Parkinson's disease?, J ournal of Neurology Neurosurgery and Psychiatry, vol. 69, 2000 , pp. 308-312.

8.LI, J., JIN, M., W ANG, L., QIN, B., A W ANG, K., MDS clinical diagnostic criteria for Parkinson's disease in China, J ournal of Neurology, vol. 264, 2017, pp. 476-481.

9.BA, F., OBAID, M., WIELER, M., CAMICIOLI, R., MARTIN, W. R. W., Parkinson Disease: The Relationship Between Non-motor Symptoms and Motor Phenotype, Canadian J ournal of Neurological Sciences / Journal Canadien des Sciences Neurologiques, vol. 43, 2016 , pp. 261-267.

10.J ENKINSON, C., CLARKE, C., GRAY, R., HEWITSON, P., IVES, N., MORLEY, D., RICK, C., WHEATLEY, K., WILLIAMS, A., Comparing results from long and short form versions of the Parkinson's disease questionnaire in a longitudinal study, Parkinsonism \& Related Disorders, vol. 21, 2015, pp. 1312-1316.

11.TODOROVA, A., J ENNER, P., AND RAY CHAUDHURI, K., Non-motor Parkinson: integral to motor Parkinson's, yet often neglected., Practical neurology, vol. 14, 2014 , pp. 310-22.

12.CREAVIN, S. T., WISNIEWSKI, S., NOEL-STORR, A. H., TREVELYAN, C. M., HAMPTON, T., RAYMENT, D., THOM, V. M., NASH, K. J. E., ELHAMOUI, H., MILLIGAN, R., PATEL, A. S., TSIVOS, D. V, WING, T., PHILLIPS, E., KELLMAN, S. M., SHACKLETON, H. L., SINGLETON, G. F., NEALE, B. E., WATTON, M. E., CULLUM, S., Mini-Mental State Examination (MMSE) for the detection of dementia in clinically unevaluated people aged 65 and over in community and primary care populations, Cochrane Database of Systematic Reviews, 2016 , p. CD011145.

13.BONDARI, S., BONDARI, D., PIRSCOVEANU, M., MORO@ANU, D. V., MUSETESCU, A. E., TUDORICA, V., AND PIRSCOVEANU, D. F. V., Study on cognitive decline in patients diagnosed with brain tumors, Romanian J ournal of Morphology and Embryology, vol. 58, 2017 , pp. 1185-1192.

14.MARTINEZ-MARTIN, P., VISSER, M., RODRIGUEZ-BLAZQUEZ, C., MARINUS, J., CHAUDHURI, K. R., VAN HILTEN, J. J., SCOPA-Propark Group, and ELEP Group, SCOPA-sleep and PDSS: Two scales for assessment of sleep disorder in Parkinson's disease, Movement Disorders, vol. 23, 2008, pp. 1681-1688.

15.SANKHLA, C., RAVAN, A., AHMAD, F. H., CHABRIA, S., GADHARI, M., Non-motor symptoms in an Indian cohort of Parkinson2 $s$ disease patients and correlation of progression of non-motor symptoms with motor worsening, Neurology India, vol. 63, 2015 , p. 166.

16.SHALASH, A. S., HAMID, E., ELRASSAS, H. H., BEDAIR, A. S., ABUSHOUK, A. I., KHAMIS, M., HASHIM, M., AHMED, N. S.-E., ASHOUR, S., AND ELBALKIMY, M., Non-Motor Symptoms as Predictors of Quality of Life in Egyptian Patients W ith Parkinson's Disease: A Cross-Sectional Study Using a Culturally Adapted 39-Item Parkinson's Disease Questionnaire, Frontiers in Neurology, vol. 9, 2018 , p. 357. 
17.J IMBOREAN, G., SZASZ, S., SZATHMARY, M., CSIPOR, A., ARGHIR, O. C., NEMES, R. M., POSTOLACHE, P., IANOSI, E. S., Association between chronic obstructive pulmonary disease and sleep apneaoverlap syndrome-experience of pulmonology clinic Tg. Mures, Romania, Rev. Chim. (Bucharest), 69, no. 4, 2018, p. 1014-1017. 18.CALBOREAN, V., CIOBANU, D., MIREA, S.C., GALCEAVA, O.,GHEORMAN, V., PADUREANU, V., FORTOFOIU, C.M., FORTOFOIU,M., MITA, A., DINESCU, S.N., MISCOCI, S.A., DINESCU, V.C. Benefit of Cardiac Resynchronization Therapy in Patients with Heart Failure. Rev. Chim. (Bucharest), 69, no. 9, 2018, p.2461-2464.
19.CALBOREAN, V., GHEORMAN,V., DINESCU, S.N., STANCA, D., GALCEAVA, O., FORTOFOIU, M., MITA, A., MIHAILOVICI, A.R., MISCOCI, S.A., BALEANU,D., DINESCU, V.C., Arrhythmia Risk in Patients with Chronic Hepatic Disease. Rev. Chim (Bucharest) 69, no. 11, 2018, p. 4237-4240.

20.van GILST, M. M., van MIERLO, P., BLOEM, B. R.OVEREEM, S., Quantitative Motor Performance and Sleep Benefit in Parkinson Disease., Sleep, vol. 38, 2015 , pp. 1567-73.

21.SANJ ARI MOGHADDAM, H., VALITABAR, Z., ASHRAF-GANJ OUEI, A., MOJ TAHED ZADEH, M., GHAZI SHERBAF, F., AARABI, M. H., Cerebrospinal Fluid C-Reactive Protein in Parkinson's Disease: Associations with Motor and Non-motor Symptoms, NeuroMolecular Medicine, vol. 20, 2018, pp. 376-385.

Manuscript received: 30.10 .2018 